\title{
Adaptive Protection System for Microgrids Based on a Robust Optimization Strategy
}

\author{
Oscar Núñez-Mata ${ }^{1,2, *}$, Rodrigo Palma-Behnke ${ }^{1}$, Felipe Valencia ${ }^{1}$, Patricio Mendoza-Araya ${ }^{1}$ (D) \\ and Guillermo Jiménez-Estévez ${ }^{1}$ \\ 1 Energy Center, Department of Electrical Engineering, Faculty of Mathematical and Physical Sciences, \\ University of Chile, 8370451 Santiago, Chile; rodpalma@cec.uchile.cl (R.P.-B.); \\ felipe.valencia@sercchile.cl (F.V.); pmendoza@ing.uchile.cl (P.M.-A.); gjimenez@centroenergia.cl (G.J.-E.) \\ 2 Electric Power and Energy Research Laboratory (EPER-Lab), School of Electrical Engineering, \\ University of Costa Rica, 11501 San José, Costa Rica \\ * Correspondence: oscar.nunezmata@ucr.ac.cr; Tel.: +506-2511-2600
}

Received: 14 December 2017; Accepted: 25 January 2018; Published: 1 February 2018

\begin{abstract}
The development of a proper protection system is essential for the secure and reliable operation of microgrids. In this paper, a novel adaptive protection system for microgrids is presented. The protection scheme is based on a protective device that includes two directional elements which are operating in an interleaved manner, namely overcurrent and undervoltage elements. The proposed protection scheme can be implemented in microprocessor-based relays. To define the settings of the protective device, a robust programming approach was proposed considering a finite set of fault scenarios. The scenarios are generated based on the predictions about the available energy and the demand. For each decision step, a robust optimization problem is solved online, which is based on forecasting with a confidence band to represent the uncertainty. The system is tested and compared using real data sets from an existing microgrid in northern Chile. To assess the performance of the proposed protection system, fault scenarios not considered in the optimization were taken into account. The results obtained show that the proposed protective device is able to manage those failure scenarios, as well as those included in the tuning of the settings. Practical considerations are also discussed.
\end{abstract}

Keywords: microgrid; optimization; power system fault; power system protection; distributed power generation

\section{Introduction}

Microgrids have received much attention in recent years since they appear as a new solution to the power supply, taking advantage of local energy resources (such as wind and solar). A microgrid is defined as a self-contained power system, which includes directly connected synchronous generator-based distributed generation (DG) units, as well as inverter-based DG units, energy storage systems, and loads, forming a controllable system [1]. Microgrids can operate while being connected to a main grid (grid-connected mode) or in isolated mode. During grid-connected mode, the microgrid receives power from both the utility and the DG units. When it is operating in isolated mode, the microgrid must autonomously meet the power requirements of the customers securely, reliably, and with adequate power quality.

When the microgrid concept was introduced in 2001 as a new solution to the power supply, it became evident that the protection requirements would be different compared to traditional power systems [2]. As detailed in [3], the differences are mainly due to the short-circuit fault currents that can change in magnitude and direction, depending on the operating conditions of the microgrid [4]. Indeed, the isolated mode operation appears the most challenging to solve, due to the absence of a bulk 
power system [5]. On the one hand, at a grid-connected microgrid, directional overcurrent protection solutions can be applied [6]. On the other hand, in an isolated microgrid, the directional overcurrent protective devices might not be sufficient, due to the possible reduced fault current magnitudes [7]. Consequently, the protection systems based on the detection of fault currents may be ineffective to protect a microgrid against short-circuit faults, and it will be necessary to propose new protection systems for its safe and reliable operation, mainly in isolated microgrids with inverter-based DGs.

Regardless of the changes in the operating conditions of the microgrid, the protection devices adjustment must be realized in such a way that its protective function meets the requirements of sensitivity, selectivity, reliability, and speed [8]. Therefore, the protection system of a microgrid must be designed to operate properly, even when facing the variability of renewable generation sources and demand, the changes in operating mode, the connection and disconnection of DG units, the changes in topology, the variety of possible fault conditions, and other planned or unplanned events. One way to overcome the difficulties in the adjustment of protective devices, imposed by the uncertainty in the operation of a microgrid, is to establish a setting group that can operate well under a variety of conditions and operational parameters. Different approaches have been applied to electrical power systems (EPS) for management and decision making under uncertainty, such as stochastic programming and robust optimization [9].

Firstly, stochastic programming has established itself as a powerful modeling tool when the probability distributions of the random variables are exactly known. However, in many EPS applications, the decision-maker does not have this information; for instance, when it comes to represent the probability of a given fault that may occur in each location of the protective zones, for use in protection coordination [10]. Secondly, robust optimization has recently gained substantial popularity as a modeling framework for optimization under parameter uncertainty [11]. Compared to the stochastic programming approach, robust optimization is more practical in that it only requires a deterministic uncertainty set. Thus, it is feasible to apply the robust optimization technique to solve the protection coordination problem, because the robust model constructs an optimal solution that immunizes against all realizations of the uncertain data within a deterministic uncertainty set [11].

To apply a robust optimization approach to the adjustment of protection devices for microgrids, it is necessary to consider the protection scheme and coordination aspects. Related to the protection scheme, one way to design an adequate protection device for microgrids is to include the information provided by several variables (in addition to the fault current) into the fault detection. For example, in [4], an approach using the voltage magnitude was proposed. In [12], a strategy for the protection of low voltage microgrids based on relays was presented, which applies to both modes of operation. This approach presents a scheme based on directional overcurrent and undervoltage devices. One of the remarkable features of this proposal is that the protective devices make decisions based on local measurements. However, such an approach did not discuss the convenience of the use of a time-voltage characteristic and did not include the calculation of the fault resistance. In [13], a work that considered the low magnitudes of fault currents using undervoltage devices was presented. However, the simulation results were obtained in a simplified microgrid, and the protection coordination method is not easily applicable to more complex microgrids.

Although the use of several variables to determine a fault condition in microgrids was widely analyzed in different cases, little attention has been paid to the coordination of these protection schemes. Nevertheless, different protection coordination methods have been proposed in power systems literature. In [14], the use of an optimization method to solve the protection coordination problem was proposed. This approach is applied to EPS, where different methods to coordinate directional overcurrent relays have been applied [15]. For instance, it has been shown that optimal linear programming can be used to optimize the time dial setting when the pickup current is previously defined using some heuristic rule [16]. In [17], a new time-current-voltage characteristic for directional relays was proposed. The new tripping characteristic integrates the fault voltage magnitude into the time-current curve, forming a three-dimensional tripping curve. The protection coordination problem 
in this case was formulated as a constrained nonlinear programming problem to determine the optimal relay settings. In [14], the protection coordination problem was formulated as an optimization problem where the primary objective was to minimize the overall relay operating time. The approach is presented as a non-linear programming problem by considering both the time dial setting and the pickup current as optimization variables. The obtained results indicated that the pickup current settings were extremely low, as explained in [18]. The aforementioned protection coordination methods conceive the optimization problem without considering the uncertainties of the different variables that could affect the performance of the protection scheme. Besides, the methods used a single operating condition and fault conditions with zero fault resistance [16]. Under these circumstances, the state-of-the-art methods cannot ensure that the protection system remains coordinated for a wide variety of scenarios, as is the case of microgrids.

The objective of this study is the development of an adaptive protection system for microgrids able to deal with a variable operating context:

- connection and disconnection of DG units and storage devices;

- changes in the operation mode of the microgrid (isolated, grid-connected);

- topology changes;

- load variations (intra-daily, daily, seasonal).

The rest of the paper is organized as follows: Section 2 presents the formulation of a robust coordination problem. Section 3 presents the methodological proposal together with its validation. In Section 4, the evaluation of the proposed method is presented. Finally, the conclusions are presented in Section 5.

\section{Formulation of the Robust Coordination Problem}

Protection coordination is a process for determining the primary protective devices responsible for clearing faults as quickly and selectively as possible. For each fault location, every protective device should be backed up by another device [19]. The first step of a protection coordination procedure is to determine the primary /backup (P/B) pairs. In a microgrid with radial topology, the coordination begins from the most remote protection device with respect to the slack node. In this particular case, each P/B pair can be determined easily. However, in microgrids with more complex structures, the selection of inception points becomes a challenge. Regardless of the microgrid configuration, an appropriate method to determine the $\mathrm{P} / \mathrm{B}$ pairs should be used, such as that presented in [20].

With $\mathrm{P} / \mathrm{B}$ pairs properly defined, we establish an optimization problem, where the objective is to minimize a certain cost function defined as $\|A x-b\|$, considering some uncertainty or possible variation in the data of $A$ and $b$. We assume that $A$ and/or $b$ are random variables with values of $\mathbb{R}^{m x n}$ and $\mathbb{R}^{m x 1}$, respectively, and $x \in \mathbb{R}^{n x 1}$. The scenario approach is used to structure uncertain input data. A scenario represents a possible realization of the uncertain input data. A specific case of the above is to model the variation in the matrix $A$ by means of a worst-case approach [21]. Here, we have a finite set of $k$ scenarios defined as: $\mathcal{A}=\left\{A_{1}, \ldots, A_{k}\right\}$. The robust criterion aims to minimize the cost function in the worst-case scenario. The problem is defined as [21]:

$$
\min \left[\max _{i=1, \ldots, k}\left\|A_{i} x-b\right\|\right]
$$

We can cast the problem in epigraph form as:

$$
\min t \quad \text { s.t. }\left\|A_{i} x-b\right\| \leq t, i=1, \ldots, k
$$

which can be solved in a variety of ways, with $t$ as the auxiliary variable.

Let $z\left(s, p_{k}\right)$ denote the cost function related to the protection coordination problem in microgrids, where $s$ represents the protection device settings; $s \in S, S$ represents the set of permissible settings; 
and $p_{k}$ represents the fault conditions, $p_{k} \in P, k=1, \ldots, K$, with $K$ being the maximum number of fault events considered, and $P$ the finite set of scenarios. The way in which the set $P$ is defined will be explained in the next section.

Thus, the coordination problem can be defined as:

$$
\begin{aligned}
\min _{\mathrm{s}} t & \text { s.t. } z\left(s, p_{k}\right) \leq t, \forall k \\
T_{i}^{\text {min }} \leq T_{i} \leq T_{i}^{\text {max }} & \text { (bounds of the } i \text { th element) } \\
g\left(s_{i}, p_{k}\right) \geq 0 & \text { (coordination criteria) }
\end{aligned}
$$

Equation (3) can be particularized to the problem of selecting the settings for a coordinated operation of directional overcurrent and undervoltage protection elements, by defining $z\left(s, p_{k}\right)$ as the sum of the operating times of all elements.

The inverse time curve of protection elements can be estimated based on standards or manufacturer data. On one side, the overcurrent element responds to a characteristic function approximated by:

$$
T_{i k}=C_{1} \frac{T D S_{i}}{\left[\left(I_{i k} / I_{i}^{p}\right)^{C_{2}}+C_{3}\right]}
$$

where $T_{i k}$ is the operating time of overcurrent element $i$ for a fault $k ; C_{1}, C_{2}$, and $C_{3}$ are constants that depend upon the kind of device being simulated; $T D S_{i}$ is the time dial setting; $I_{i k}$ is the short-circuit current measured at the secondary winding of the current transformer of protection device $i$ with $R_{f}=0$; and $I_{i}^{p}$ is the pickup current value of the protection device $i$. If $I_{i}^{p}$ is assumed to be known, (4) can be rewritten linearly for a specific fault current as:

$$
T_{i k}=M_{i k} T D S_{i}
$$

where:

$$
M_{i k}=\frac{C_{1}}{\left[\left(I_{i k} / I_{i}^{p}\right)^{C_{2}}+C_{3}\right]}
$$

On the other side, in this proposal, the undervoltage element responds to a characteristic function approximated by:

$$
T_{j k}=\frac{D_{j}}{\left[1-\left(V_{j k} / V_{j}^{p}\right)\right]}
$$

where $T_{j k}$ is the operating time of undervoltage element $j$, for a fault $k ; D_{j}$ is the time dial setting; $V_{j k}$ is the short-circuit voltage measured at the secondary winding of the potential transformers of device $j$ during a fault with $R_{f}=R_{f}^{\max }$; and $V_{j}^{p}$ is the pickup voltage value of device $j$. The undervoltage element is inhibited from acting on faults with $R_{f}=0$ by means of a minimum voltage setting. This setting selects the operating voltage below which the element is blocked.

If $V_{j}^{p}$ is assumed to be known, (7) can be rewritten linearly for a specific fault voltage as:

$$
T_{j k}=L_{j k} D_{j}
$$

where:

$$
L_{j k}=\frac{1}{\left[1-\left(V_{j k} / V_{j}^{p}\right)\right]}
$$


Therefore, using (5) and (8), the problem can be represented as a linear programming model, with $M_{i k}$ and $L_{j k}$ named as the characteristic-curve factors of the protection elements. Finally, the coordination problem is defined as:

$$
\begin{gathered}
\min _{T D S_{i}, D_{j}} t \text { s.t. }\left\{\sum_{i=1}^{O}\left(M_{i k} T D S_{i}\right)+\sum_{j=1}^{U}\left(L_{j k} D_{j}\right)\right\} \leq t, \forall k \\
T_{i k}^{\text {min }} \leq T_{i k} \leq T_{i k}^{\text {max }} \\
T_{j k}^{\text {min }} \leq T_{j k} \leq T_{j k}^{\text {max }} \\
T_{b k} \geq T_{i k}+\Delta T_{i b} \\
T_{j k} \geq T_{i k}+\Delta T_{i j}
\end{gathered}
$$

where $O$ and $U$ are the number of overcurrent and undervoltage protective elements, respectively; $T_{i k}^{\min }-T_{i k}^{\max }$ and $T_{j k}^{\min }-T_{j k}^{\max }$ are, respectively, the bounds on the operation times for the overcurrent and undervoltage elements; $T_{b k}$ is the operating time of the first backup overcurrent protection of device $i ; \Delta T_{i b}$ is the coordination time interval (CTI) for the overcurrent devices $i$ and $b$; and $\Delta T_{i j}$ is the CTI for the overcurrent device $i$ and the undervoltage device $j$. It is worth noting that, in this proposal, the undervoltage element is defined as a backup of the overcurrent device.

For the transient configurations that can occur, [8] has recommended including coordination criteria using an additional constraint as follows:

$$
T_{b k}^{\prime} \geq T_{i k}^{\prime}+\Delta T_{i b}^{\prime}
$$

where the superscript (') corresponds to a transient configuration when only one protection device of a zone has operated.

\section{Methodology Framework and Validation}

\subsection{Description of the Proposed Method}

The proposed robust coordination procedure is embedded in an updated version of the microgrid protection framework presented by the authors in [22]. Thus, the protection system is composed of two main units, namely a Monitoring and Diagnostic Unit (MDU) and a Dynamic Protection Adjustment Unit (DPAU), as is presented in Figure 1.

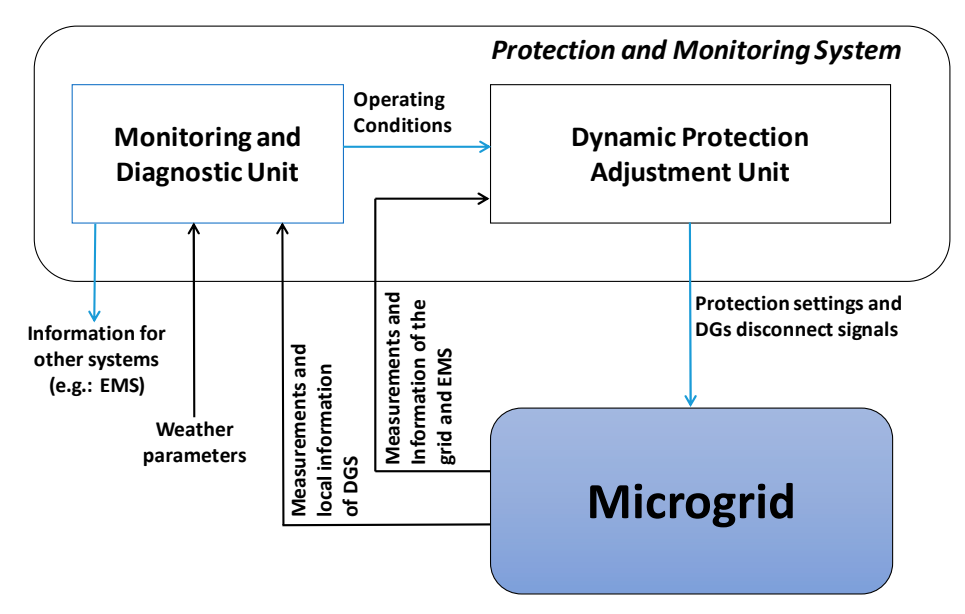

Figure 1. Proposed protection and monitoring system for microgrids. 
The MDU verifies the operating conditions of the energy sources with a model-based approach. The model-based method estimates the operating condition of each energy source based on real measurements and model-generated data, comparing the measurements with the theoretical model. If an abnormal operating condition is detected, this unit sends the information to the DPAU, indicating that the generation capabilities of the energy sources have been reduced. Otherwise, in a normal operating condition, this unit sends the power currently supplied by the energy source to the DPAU. In the case that a severe fault is detected, the MDU can send the disconnect signal of the affected energy source.

The DPAU of Figure 1 is responsible for defining the settings of the protection devices. The proposed DPAU is based on an adaptive coordination approach, where the protective devices are readjusted to accomplish the fault detection requirements arising from the changes in the operating conditions. The DPAU works online in a triggered-event manner. A diagram with all the stages of the proposed methodology is shown in Figure 2, including the robust coordination procedure presented in Section 2, as the final stage.

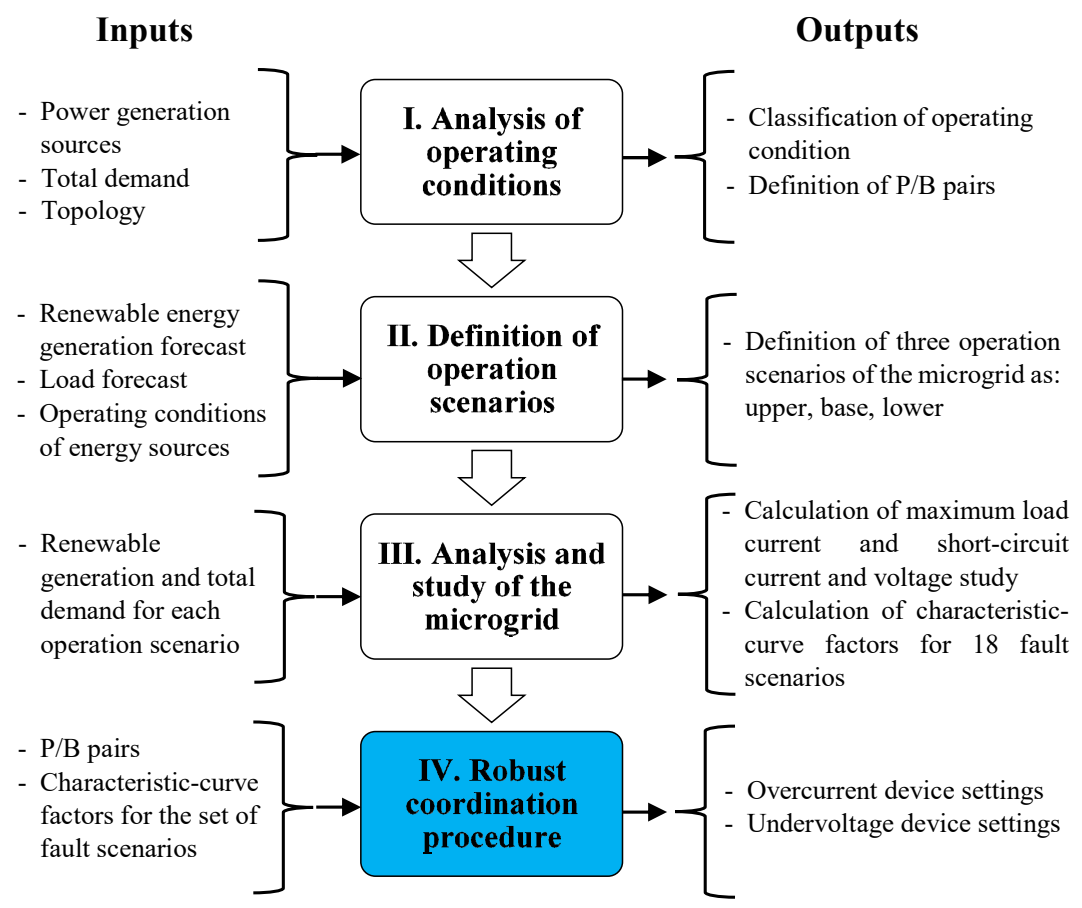

Figure 2. Four-stage procedure for the DPAU.

Each of the stages shown in Figure 2 is detailed below.

\subsubsection{Analysis of Operating Conditions}

The DPAU follows the evolution of the operating conditions of the microgrid, including the information sent from the MDU. The objective of this stage is to evaluate those aspects that influence the operation of the protection system, whether they cause degradation of the sensitivity, changes in the speed, or the loss of the coordination. When a change in the classification of the operating condition is presented, then the methodology for adjusting protections is executed. If not, the settings are maintained until a relevant change occurs. The following aspects are considered when deciding whether to start the readjustment methodology:

- Changes in the operating mode.

- Changes in the DG units and energy storage systems.

- Changes in the topology. 
- Changes in the net load parameter $(N L)$, defined as follows:

$$
N L=P_{L}-P_{R E}
$$

where $P_{L}$ is the total load and $P_{R E}$ is the generation of renewable energy sources.

According to the $N L$ value, the operating condition of the microgrid is classified based on a threshold, which depends on the particular characteristics of the microgrid. The NL parameter might be affected by load management executed in the microgrid. For example, strategies such as demand response or energy management system (EMS) actions could change the value of NL. Even though load management systems could be helpful while operating in abnormal conditions (e.g., an overload in a distribution line), the methodology does not contemplate interaction with such systems at the moment.

This step also involves the definition of the $\mathrm{P} / \mathrm{B}$ pairs following the methodology presented in [20].

\subsubsection{Definition of the Operation Scenarios}

The operation scenarios are defined considering historical data and forecast of energy generation with renewable sources and demand, and establishing a confidence interval to represent the uncertainty. Besides, the generation capabilities of the energy sources are adjusted with data received from the MDU, if necessary (e.g., reduction in electricity production capacity by excessive dust on the modules of a photovoltaic (PV) plant). Thus, the operation scenarios are defined as follows:

1. Get the initial condition for $t=t_{\text {current }}$.

2. The DPAU asks for renewable generation and a load forecast for the next forecasting horizon $T$. Several conventional forecasting methods can be applied for this purpose [23].

3. For a defined confidence band, the following three different operation scenarios are considered: upper band limit, base, and lower band limit.

This approach corresponds to a rolling horizon strategy as is presented in [23]. It is important to note that the refresh rate of the analysis depends on the specific energy management system (EMS) implementation. It should be high enough to follow the sudden changes of operating mode, demand, topology, and non-dispatchable generators.

\subsubsection{Analysis and Study of the Microgrid}

For each operation scenario, a three phase power flow study is performed [24]. In this work, it is assumed that all the information to perform a power flow study is available. Consequently, pickup current values are determined as the maximum current of the three simulated scenarios plus a security margin of $20 \%$. This parameter directly affects the sensitivity of the protection device and must be updated for the different operating conditions.

Then, a three-phase short-circuit analysis is executed considering three fault locations, defined at $1 \%, 50 \%$, and $99 \%$ of the length of each protected line. Different methods have been proposed for the calculation of short-circuit currents in microgrids with the presence of DG units of different types. Superposition strategies or iterative short-circuit methods can be used for this purpose [25]. Thus, with an appropriate method, the short-circuit currents with zero fault resistance $\left(R_{f}=0\right)$ are calculated. These values are the maximum fault currents expected in the different locations of the microgrid, which are useful for both defining the rating of the components and applying the methodology for adjusting protective devices. In addition, with the maximum fault current $\left(I_{i k}\right)$, we propose to calculate the maximum fault resistance $\left(R_{f}^{\max }\right)$ based on [26].

The fault resistance concept refers to the resistance of the electric arc that usually appears in a short-circuit fault, which can be included in the calculations. This fault resistance will limit the short-circuit current and will change the voltage drop during a short-circuit. An electric arc is a non-linear phenomenon that depends on diverse factors; however, there are several approaches that 
consider the arc as a single resistance, which depends on the current and the arc length. Thus, based on experimental testing, the following equation for fault resistance is used [26]:

$$
R_{f}^{\max }=\frac{1443.57 L}{I_{i k}}
$$

where $R_{f}^{\max }$ is measured in ohms, $L$ is the arc length in meters, $I_{i k}$ is the maximum short-circuit fault current in amperes in (4), and 1443.57 is the arc voltage gradient, which is a constant obtained experimentally, and measured in $[\mathrm{V} / \mathrm{m}]$.

The final step is to calculate the short-circuit currents with $R_{f}^{\max }$ for all the combinations of locations/scenarios. These currents will be the lowest expected fault currents, for which the protection system must act. Together with the fault currents, the fault voltages must be computed with $R_{f}^{\max }$ in order to adjust the undervoltage devices.

\subsubsection{Robust Coordination Procedure}

The methodology continues with the procedure for adjusting the protective devices using a set of fault scenarios developed in the previous stage. The objective of the robust optimization is to hedge against the risk of system performance degradation on a set of possible scenarios while maintaining an appropriate system performance. Consequently, a protective device setting is said to be robust, if it clears the fault in a timely manner and remains properly coordinated for a set of feasible operation scenarios of the microgrid. This set of scenarios also aims to cover other less critical operation conditions calculated in the previous stage (database of short circuit currents for each operation scenario (three), fault resistance (two), and line location (three)). Thus, with $K=18$, a set $\mathcal{A}=\left\{A_{1}, \ldots, A_{18}\right\}$ is developed (according to Section 2). In this case, $A_{k} \in \mathbb{R}^{m x n}$ and $x \in \mathbb{R}^{n x 1}$, where $m$ is the number of characteristic-curve factors of the protection elements, and $n$ is the number of time dial settings of overcurrent and undervoltage elements. Finally, the parameter $b$ is zero.

The robust optimization procedure considers that the settings of the protective devices will take discrete values (as it is with current electronic protective devices). Therefore, it is necessary to define them as discrete variables, according to the resolution of each particular protective device.

\subsection{Validation of the Methodological Proposal}

In this subsection, the results obtained for the application of the methodology on the IEEE 37-node test feeder are presented. Detailed specifications of the feeder can be found in [27]. A few modifications in the original test feeder are incorporated, as shown in Figure 3. In the distribution grid, two power units have been installed as follows: (i) battery energy storage system (BESS) at node 701, 5 [MW], interfaced with a voltage-source-inverter, and with a maximum fault current of 2 [p.u.] according to [28]; and (ii) 3 [MW] PV plant at node 720, controlled with a current-source-inverter, and with a maximum fault current of 1.5 [p.u.] according to [28]. Besides, overcurrent and undervoltage protective devices were included along the central feeder. Finally, balanced loads were considered. 


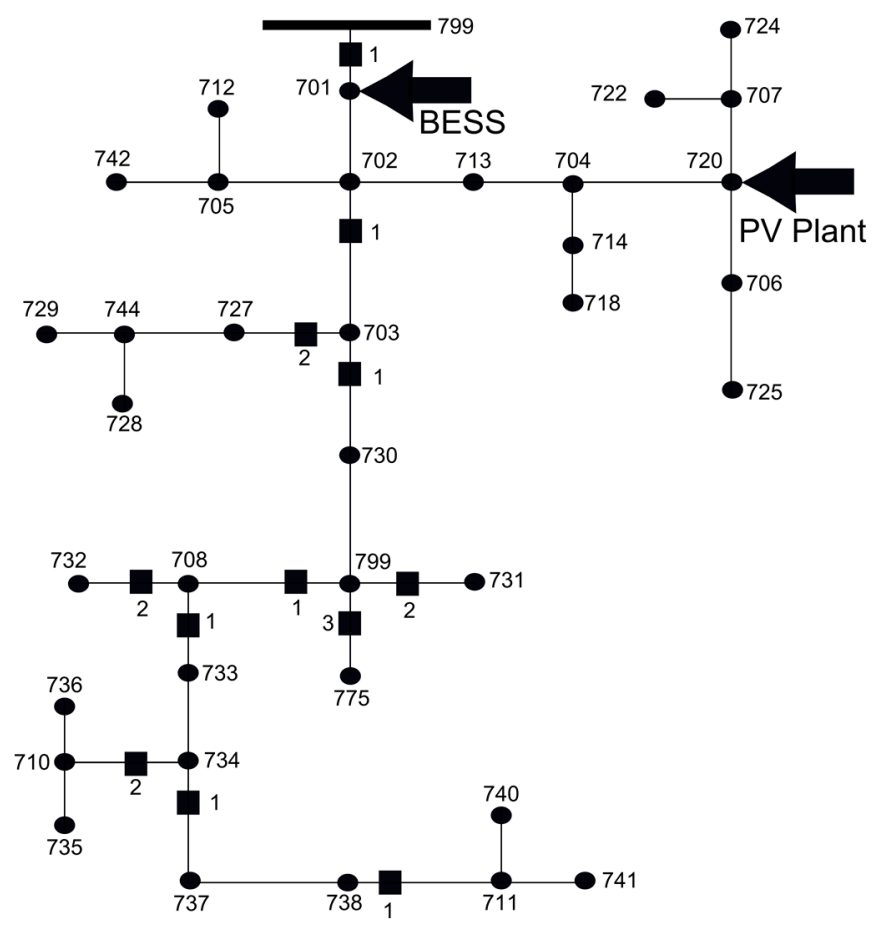

Figure 3. Modified IEEE 37-node test feeder for validation of the methodology.

For one operating condition, three operation scenarios were considered in isolated mode (i.e., protection device in node 799 opened), taking into account the test feeder specifications as follows: (i) upper scenario: considering the rated load of the operating condition, supplied by the PV plant at 3 [MW], and the BESS being charged; (ii) base scenario: with 3\% lower load; and, (iii) lower scenario: with $6 \%$ lower load. With these considerations, the proposed methodology was applied to obtain the protective device settings.

A commonly used methodology was used for comparison purposes [17]. In this alternative methodology, the protection coordination problem is solved using a linear programming method, applied for a single operation scenario. In both the proposed and the alternative methodologies, the pickup currents were calculated as 1.2 times the maximum load current, and the pickup voltages as 0.85 times the rated voltage of $4.8[\mathrm{kV}]$. Table 1 shows the results of both methodologies.

Table 1. Obtained results of modified IEEE 37-node system.

\begin{tabular}{|c|c|c|c|c|c|c|c|c|}
\hline \multirow[t]{2}{*}{ Bus No. } & \multirow{2}{*}{$\begin{array}{l}\text { Primary } \\
\text { Device }\end{array}$} & \multirow{2}{*}{$\begin{array}{c}\text { Current } \\
\text { Pickup [A] }\end{array}$} & \multirow{2}{*}{$\begin{array}{c}\text { Voltage } \\
\text { Pickup [V] }\end{array}$} & \multirow{2}{*}{$\begin{array}{l}\text { Backup } \\
\text { Device }\end{array}$} & \multicolumn{2}{|c|}{$\begin{array}{l}\text { Settings with Proposed } \\
\text { Methodology }\end{array}$} & \multicolumn{2}{|c|}{$\begin{array}{l}\text { Settings with Alternative } \\
\text { Methodology }\end{array}$} \\
\hline & & & & & $T D S_{i}[\mathrm{~s}]$ & $D_{j}[\mathrm{~s}]$ & $\operatorname{TDS}_{i}[\mathrm{~s}]$ & $D_{j}[\mathrm{~s}]$ \\
\hline 702 & 1 & 230 & 4080 & - & 0.14 & 0.47 & 0.22 & 0.40 \\
\hline \multirow{2}{*}{703} & 1 & 160 & 4080 & \multirow[b]{2}{*}{$702-1$} & 0.14 & 0.37 & 0.14 & 0.35 \\
\hline & 2 & 50 & 4080 & & 0.05 & 0.13 & 0.05 & 0.12 \\
\hline \multirow{3}{*}{709} & 1 & 120 & 4080 & \multirow{3}{*}{ 703-1 } & 0.13 & 0.33 & 0.13 & 0.31 \\
\hline & 2 & 20 & 4080 & & 0.05 & 0.12 & 0.05 & 0.12 \\
\hline & 3 & 45 & 4080 & & 0.08 & 0.10 & 0.08 & 0.10 \\
\hline \multirow{2}{*}{708} & 1 & 110 & 4080 & \multirow{2}{*}{$709-1$} & 0.10 & 0.26 & 0.10 & 0.25 \\
\hline & 2 & 20 & 4080 & & 0.05 & 0.12 & 0.05 & 0.12 \\
\hline \multirow{2}{*}{734} & 1 & 70 & 4080 & \multirow{2}{*}{ 708-1 } & 0.08 & 0.20 & 0.08 & 0.20 \\
\hline & 2 & 25 & 4080 & & 0.05 & 0.13 & 0.05 & 0.13 \\
\hline 738 & 1 & 25 & 4080 & 734-1 & 0.05 & 0.14 & 0.05 & 0.14 \\
\hline
\end{tabular}


The time dial settings $T D S_{i}$ and $D_{j}$ obtained with the proposed methodology for the first feeder protective devices were lower than those of the alternative methodology. However, towards the end of the feeder, the setting results were similar with both methodologies. The obtained values indicate that the proposed methodology resulted in better overall settings compared to the alternative methodology, also ensuring a coordinated operation.

\subsection{Practical Considerations}

The practical implementation of the proposed protection and monitoring system, shown in Figure 1, can be divided into three levels, according to the functions to be performed, as follows:

1. The first level comprises field devices, such as controllers, actuators, protective devices, and sensors, all of which are deployed on the entire microgrid. The controllers and actuators perform the control actions on the microgrid. The protective devices are adjustable and provide the remote trip capacity. The sensors are the main components for achieving accurate and reliable field data.

2. The second level is the data acquisition layer, which channels the communications within the microgrid. It requires specific hardware and communication networks.

3. The final level corresponds to the protection and monitoring system, where the procedures for diagnostics and adjustment of protective devices are executed. This is the realization of the MDU and DPAU.

Technical requirements and recommendations for the protection relays of an adaptive protection system in microgrids are:

- The use of microprocessor-based directional relays that include overcurrent and under voltage elements is necessary.

- The relays must have the possibility of using different tripping characteristics (i.e., several settings groups) that can be configured locally or remotely, automatically or manually.

- The use of a communication infrastructure that uses standard communication protocols is required. By doing so, individual relays can communicate and exchange information with the protection and monitoring system, or between different individual relays, in a fast and reliable manner, guaranteeing the required application performance.

\section{Study Case and Results}

\subsection{Description of the ESUSCON Microgrid}

The proposed methodology was tested on an existing microgrid installed in Huatacondo, a remote town located in northern Chile. The ESUSCON microgrid (by the acronym in Spanish of Electricidad Sustentable Cóndor) is a PV isolated microgrid implemented to provide a continuous supply of electricity to approximately 100 people [28]. In Figure 4, the single line diagram of the microgrid is shown. The demand is supplied by the DG units and energy storage system shown in Table 2. The low voltage distribution grid comprises overhead power lines. Parameters of the distribution lines are shown in Table A1 in the Appendix A. 


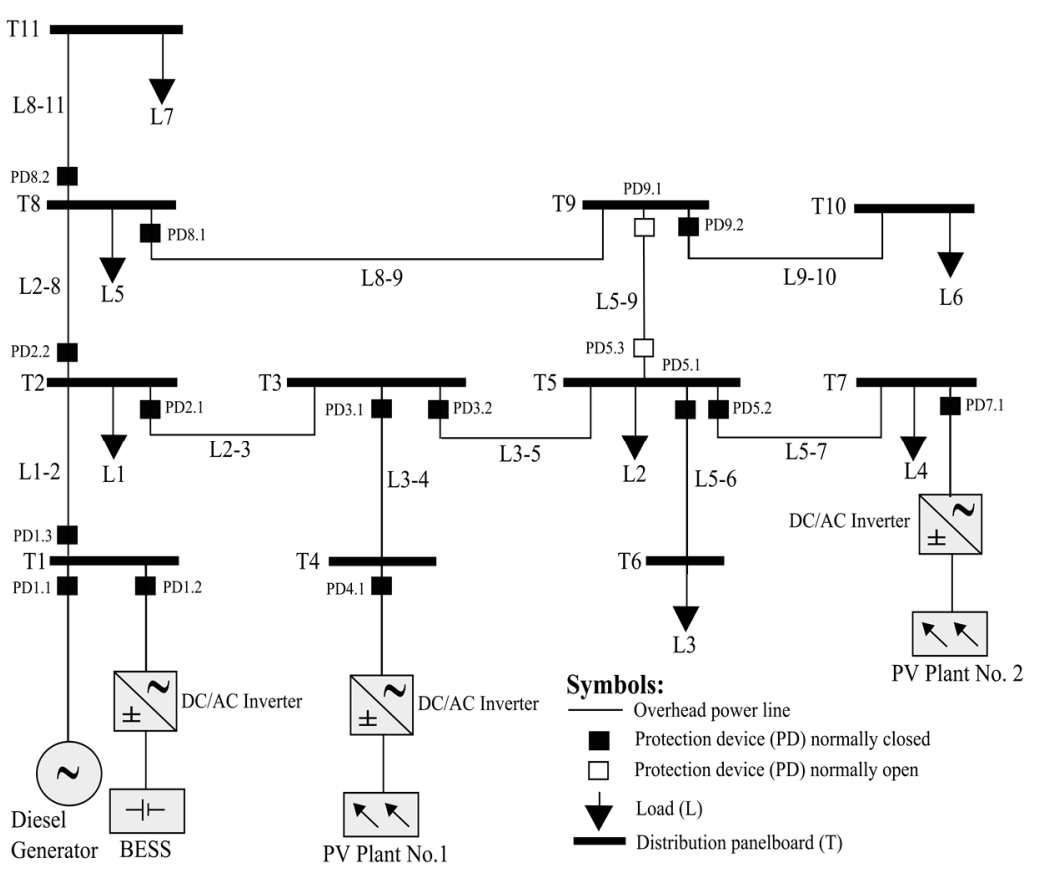

Figure 4. Single line diagram of the ESUSCON microgrid.

Table 2. Distributed generation units' ratings of the microgrid.

\begin{tabular}{ccccc}
\hline No. & Bus No. & Unit & Rated Power & Electrical Data and Others \\
\hline 1 & T1 & Diesel generator & $120[\mathrm{~kW}]$ & $220 / 380[\mathrm{~V}]$, 3-phase, 50 [Hz], synchronous machine \\
2 & T1 & BESS & $40[\mathrm{~kW}]$ & $220 / 380[\mathrm{~V}], 3-$-phase, 50 [Hz], with inverter \\
3 & T4 & PV Plant \#1 & $50[\mathrm{~kW}]$ & $220 / 380[\mathrm{~V}]$, 3-phase, 50 [Hz], with inverter \\
4 & T7 & PV Plant \#2 & $10[\mathrm{~kW}]$ & $220 / 380[\mathrm{~V}]$, 3-phase, 50 [Hz], with inverter \\
\hline
\end{tabular}

In the ESUSCON microgrid, the energy sources are coordinated by means of an EMS. The EMS supervises the energy sources and dispatches the operation modes for the Diesel generator and the BESS. To make the different adjustments, the EMS considers the following inputs: (i) state of charge of the BESS; (ii) the weather conditions, mainly sunlight; and (iii) the expected demand level.

Regarding the existing protective scheme, it was developed by installing circuit breakers with fixed settings. This protection system has problems clearing short-circuits, as was demonstrated in [29], mainly due to the significantly lower fault current level in operating conditions with inverter interfaced units only. Therefore, it is necessary to redesign the protection system in order to adequately respond to the short-circuit faults. The new protection system must ensure the following requirements: (i) isolate the faulted section from the rest of the microgrid; (ii) decrease the outage time; (iii) detect faults regardless of the current fault level; (iv) adapt to changes in the microgrid; and (v) not adversely affect the reliability and stability.

\subsection{Application of the Proposed Methodology and Discussion}

Statistics for fault occurrence are not currently available for the ESUSCON microgrid. There are only occasional fault reports, especially those that have led to the complete disconnection of the microgrid due to short-circuit faults. Given the uncertainty of the data, the reliability of the current protection system cannot be studied and assured. Therefore, the robust optimization methodology for the optimal coordination of protective devices is suggested.

In this study case, the energy sources have a circuit breaker with fixed settings, because the Diesel generators and DC/AC inverters are protected by built-in protective devices. The circuit breakers 
deployed in the distribution grid include adjustable settings capabilities. The PDAU will adjust these circuit breakers for an adaptive operation.

Considering a PV-based microgrid, its operation follows the behavior of solar irradiance. In addition, the behavior of the demand has been studied according to the hours of the day. Therefore, the NL parameter is defined as a function of the time of day according to the solar irradiance. For this case study, two different $N L$ parameters are selected, based on real operating data of the microgrid. The aim is to demonstrate the relevance of using this parameter to classify the operating condition.

The application of the procedure shown in Figure 2 starts with Stage I (analysis of operating conditions). The two different operating conditions selected were as follows:

- Operating condition at 2 p.m.: it is characterized by a low demand, which is supplied exclusively by the PV plants and the BESS is being charged. The Diesel generator is off. Thus, the NL parameter is classified as Low.

- Operating condition at 11 p.m.: it is characterized by high demand. This is supplied by the Diesel generator, and the BESS is being charged. The PV plants are off. Thus, the NL parameter is classified as High.

Consequently, distinct protection settings are expected for both cases.

To develop Stage II (definition of the operation scenarios), the load demand, Diesel generation, and solar PV generation data are obtained from the microgrid operator, as well as the load and solar power forecasts. The forecasts have a time resolution of $15 \mathrm{~min}(T=15$ [min]).

Stage III (analysis and study of the microgrid) was done with the information compiled for each operation scenario. Power flow studies and three-phase short-circuit studies were done using the software DIgSILENT Power Factory. On the one hand, the Diesel generator was modeled as a synchronous machine, using a built-in model in Power Factory, setting the parameters and rated values of the real generator. On the other hand, the BESS and PV plants were modeled as a voltage-source-inverter and current-source-inverters respectively, all using built-in models in Power Factory with parameters of the real units. In this study case, the BESS fault current was limited to two times its rated current, and the fault currents of the PV plants were each limited to 1.5 times their rated current. The inverter fault current must be limited to a maximum value due to the rating of the semiconductor switching devices and their thermal limit.

The calculation of the $R_{f}^{\max }$ was performed using (13), with $\mathrm{L}=0.15[\mathrm{~m}]$, according to the maximum distance between conductors in the distribution grid of the ESUSCON microgrid. $R_{f}^{\max }=1.5 \Omega$ at 2 p.m. operating condition, and $R_{f}^{\max }=0.65 \Omega$ at 11 p.m. operating condition. At the end, a set of 18 fault scenarios were defined for each operating condition, as is shown in Figure 5.

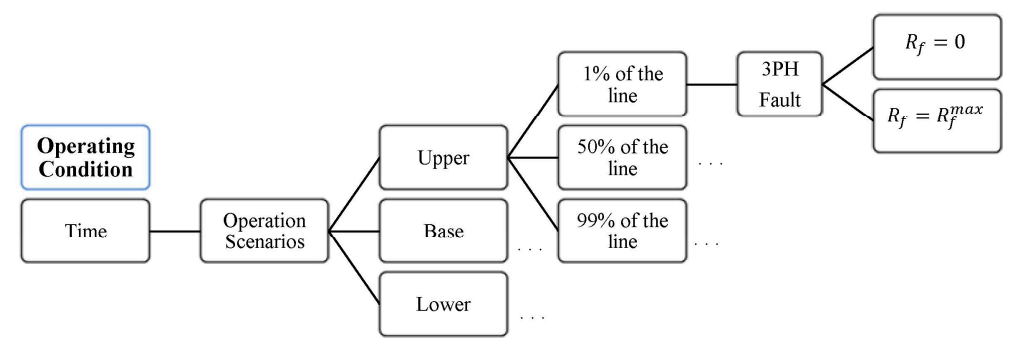

Figure 5. Definition of the set of fault scenarios for robust optimization procedure.

Finally, Stage IV (robust coordination procedure) of Figure 2 was performed to obtain the protective device settings. The following considerations were taken: time dial settings of the overcurrent and undervoltage protection elements are adjusted in discrete steps of 0.01 [s], and the minimum values are: 0.05 [s] for overcurrent element and 0.00 [s] for undervoltage element. Additionally, the minimum voltage setting is 50 [V]. Table 3 shows the robust optimization results. 
Table 3. Obtained results of ESUSCON microgrid settings in two operating conditions.

\begin{tabular}{|c|c|c|c|c|c|c|c|c|c|}
\hline \multirow[t]{2}{*}{ Bus No. } & \multirow{2}{*}{$\begin{array}{l}\text { Main } \\
\text { Device }\end{array}$} & \multicolumn{3}{|c|}{$\begin{array}{l}\text { Settings with Proposed } \\
\text { Methodology (A)-11 p.m. }\end{array}$} & \multicolumn{3}{|c|}{$\begin{array}{l}\text { Settings with Proposed } \\
\text { Methodology (A)-2 p.m. }\end{array}$} & \multicolumn{2}{|c|}{$\begin{array}{l}\text { Settings with Alternative } \\
\text { Methodology (B)-2 p.m. }\end{array}$} \\
\hline & & $I_{i}^{p}[\mathrm{~A}]$ & $\operatorname{TDS}_{i}[\mathrm{~s}]$ & $D_{J}[\mathrm{~s}]$ & $I_{i}^{p}[\mathrm{~A}]$ & $\operatorname{TDS}_{i}[\mathrm{~s}]$ & $D_{J}[\mathrm{~s}]$ & $\operatorname{TDS}_{i}[\mathrm{~s}]$ & $D_{J}[\mathrm{~s}]$ \\
\hline $\mathrm{T} 1$ & PD1.3 & 125 & 0.11 & 0.16 & 70 & 0.07 & 0.17 & 0.06 & 0.14 \\
\hline \multirow{2}{*}{$\mathrm{T} 2$} & PD2.1 & 70 & 0.13 & 0.16 & 65 & 0.06 & 0.13 & 0.05 & 0.12 \\
\hline & PD2.2 & 45 & 0.09 & 0.15 & 35 & 0.11 & 0.14 & 0.09 & 0.11 \\
\hline \multirow{2}{*}{ T3 } & PD3.1 & 65 & 0.05 & 0.10 & 65 & 0.05 & 0.03 & 0.05 & 0.02 \\
\hline & PD3.2 & 40 & 0.09 & 0.14 & 20 & 0.08 & 0.10 & 0.08 & 0.09 \\
\hline \multirow{2}{*}{ T5 } & PD3.1 & 10 & 0.05 & 0.10 & 10 & 0.05 & 0.06 & 0.05 & 0.06 \\
\hline & PD3.2 & 30 & 0.05 & 0.10 & 15 & 0.05 & 0.07 & 0.05 & 0.06 \\
\hline \multirow{2}{*}{$\mathrm{T} 8$} & PD8.1 & 55 & 0.06 & 0.13 & 30 & 0.09 & 0.13 & 0.06 & 0.09 \\
\hline & PD8.2 & 10 & 0.05 & 0.10 & 10 & 0.05 & 0.07 & 0.05 & 0.07 \\
\hline T9 & PD9.2 & 10 & 0.05 & 0.10 & 10 & 0.05 & 0.10 & 0.05 & 0.09 \\
\hline
\end{tabular}

Firstly, as shown in Table 3, the time dial settings for the overcurrent devices are lower at the 2 p.m. condition, compared to the 11 p.m. condition, which means that the methodology selected a lower curve given the low fault currents. For undervoltage devices, the settings are higher at the 11 p.m. condition, since at this condition, the high fault currents allow them to be cleared by the overcurrent element. Secondly, the settings of the devices obtained with the alternative methodology were slightly lower than or the same as those of the proposed methodology. However, the coordination margins are narrower in the alternative methodology, compared to the proposed methodology. In other words, the coordination margin is lower in the alternative methodology, which could lead to the uncoordinated operation of protective devices.

RMS fault simulations in all lines of the microgrid were performed to compare the effectiveness of both methodologies. The following short-circuit faults were made: three-phase (3PH), phase-to-phase (L-L), phase-to-phase-to-ground (2LG), and one-phase-to-ground (1LG), with zero and maximum fault resistance. Besides, three fault locations were considered, defined at 1\%,50\%, and 99\% of the length of each line. Regarding the current contributions during a fault, the inverter-basedand rotating-machine-based units show different behavior. On the one hand, the fault current exhibited by the Diesel generator depends on the pre-fault voltage and the machine's sub-transient and transient reactance. On the other hand, the short-circuit currents of the PV plants and the BESS are controlled by the internal control loops, and are limited by settings.

Table 4 shows the results obtained in L9-10 for comparison purposes. Note that the OC and UV indication in Table 4 shows which protective element was activated.

Table 4. Obtained results of RMS simulations in Line L9-10 with settings of Table 3 at 2 p.m. operating condition.

\begin{tabular}{clllcccc}
\hline & & \multicolumn{5}{c}{ Location on the Line Based on the Total Distance } \\
\cline { 3 - 7 } Fault Type & \multirow{2}{*}{$\begin{array}{c}\text { Fault } \\
\text { Resistance }\end{array}$} & \multicolumn{3}{c}{$\mathbf{1 \%}$} & \multicolumn{2}{c}{$\mathbf{5 0 \%}$} \\
\cline { 3 - 8 } & & $\begin{array}{c}\text { Clearing Time } \\
\text { with (A) [s] }\end{array}$ & $\begin{array}{c}\text { Clearing Time } \\
\text { with (B) [s] }\end{array}$ & $\begin{array}{c}\text { Clearing Time } \\
\text { with (A) [s] }\end{array}$ & $\begin{array}{c}\text { Clearing Time } \\
\text { with (B) [s] }\end{array}$ & $\begin{array}{c}\text { Clearing Time } \\
\text { with (A) [s] }\end{array}$ & $\begin{array}{c}\text { Clearing Time } \\
\text { with (B) [s] }\end{array}$ \\
\hline \multirow{2}{*}{$3 \mathrm{PH}$} & $R_{f}=0$ & $0.114(\mathrm{OC})$ & $0.117(\mathrm{OC})$ & $0.115(\mathrm{OC})$ & $0.117(\mathrm{OC})$ & $0.115(\mathrm{OC})$ & $0.118(\mathrm{OC})$ \\
& $R_{f}=R_{f}^{\max }$ & $0.147(\mathrm{OC})$ & $0.152(\mathrm{OC})$ & $0.148(\mathrm{OC})$ & $0.153(\mathrm{OC})$ & $0.148(\mathrm{OC})$ & $0.153(\mathrm{OC})$ \\
\hline \multirow{2}{*}{$\mathrm{L}-\mathrm{L}$} & $R_{f}=0$ & $0.176(\mathrm{OC})$ & $0.183(\mathrm{OC})$ & $0.177(\mathrm{OC})$ & $0.184(\mathrm{OC})$ & $0.177(\mathrm{OC})$ & $0.184(\mathrm{OC})$ \\
& $R_{f}=R_{f}^{\max }$ & $0.107(\mathrm{UV})$ & $0.094(\mathrm{UV})$ & $0.108(\mathrm{UV})$ & $\mathbf{0 . 0 9 4}(\mathrm{UV})$ & $0.108(\mathrm{UV})$ & $\underline{\mathbf{0 . 0 9 5}(\mathrm{UV})}$ \\
\hline \multirow{2}{*}{$2 \mathrm{LG}$} & $R_{f}=0$ & $0.143(\mathrm{OC})$ & $0.148(\mathrm{OC})$ & $0.144(\mathrm{OC})$ & $0.148(\mathrm{OC})$ & $0.144(\mathrm{OC})$ & $0.149(\mathrm{OC})$ \\
& $R_{f}=R_{f}^{\max }$ & $0.169(\mathrm{UV})$ & $0.149(\mathrm{UV})$ & $0.175(\mathrm{UV})$ & $0.155(\mathrm{UV})$ & $0.178(\mathrm{UV})$ & $0.158(\mathrm{UV})$ \\
\hline \multirow{2}{*}{ 1LG } & $R_{f}=0$ & $0.185(\mathrm{OC})$ & $0.192(\mathrm{OC})$ & $0.185(\mathrm{OC})$ & $0.193(\mathrm{OC})$ & $0.186(\mathrm{OC})$ & $0.193(\mathrm{OC})$ \\
& $R_{f}=R_{f}^{\max }$ & $0.228(\mathrm{OC})$ & $0.241(\mathrm{OC})$ & $0.229(\mathrm{OC})$ & $0.241(\mathrm{OC})$ & $0.229(\mathrm{OC})$ & $0.242(\mathrm{OC})$ \\
\hline
\end{tabular}


The results showed a similar performance in both methodologies. However, in two fault conditions of the type L-L short-circuit, the alternative methodology failed to clear the fault (see bolded and underlined results in Table 4), since it operated in an uncoordinated manner. The indicated time corresponds to the clearing time of the backup device. This implied that a larger area of the microgrid was disconnected due to these fault conditions.

The same analysis performed in the 2 p.m. operating condition was also performed in the 11 p.m. condition. The obtained results were slightly different from the 2 p.m. condition since the Diesel generator is connected in the 11 p.m. operating condition. In the latter, the overcurrent elements were responsible for clearing most faults.

As it can be seen, the new methodology can achieve better overall operating times compared to the methodology found in the literature. Specifically, the alternative methodology failed in two fault conditions in Line L9-10.

\section{Conclusions}

The challenge of protecting microgrids using an adaptive approach was studied in this paper. A methodological proposal for adjusting the settings of the protective devices according to the operating conditions of a microgrid, using robust optimization, is proposed. The use of robust optimization in the application context offers a novel tool to deal with the uncertainties faced in the operation of microgrids with a high penetration of variable energy sources.

We have demonstrated that under a well-defined set of fault scenarios, proper protective device settings can be calculated for variable operating conditions. Therefore, the sensitivity, selectivity, and speed of the protection system can be achieved. The proposed methodology was compared against a commonly used alternative methodology. The main outcome of the comparative study was that the methodological proposal exhibits a better solution than the alternative methodology because it performed well for the tested fault conditions that were not considered in the formulation of the optimization problem. The good performance of the proposed methodology is a result of the novel way in which the set of fault scenarios is established, and the use of a protection scheme that combines two protection elements.

Future work will focus on testing the proposed methodology in microgrids with meshed configurations where transient configurations can occur. Additionally, reliability issues related to failures in the communication system should be systematically addressed, to ensure the proper operation of the protection system in this condition. Finally, the corrective actions performed by load management systems should be considered in this methodology, in order to improve the performance of the protection system.

Acknowledgments: This research was supported by the FONDAP/CONICYT, grant number 15110019, the FONDECYT 1151438, and the University of Costa Rica. We would like to thank the company FICO for providing us with a license and a copy of the optimization software.

Author Contributions: Oscar Núñez-Mata developed the review of the state of the art. Then, together with Rodrigo Palma-Behnke, they developed the first discussions about the different components of the proposed methodology. Oscar Núñez-Mata, Rodrigo Palma-Behnke and Felipe Valencia conceived and designed the robust optimization strategy. Oscar Núñez-Mata, Patricio Mendoza-Araya and Guillermo Jiménez-Estévez developed the test case definition and conducted the experiments, simulations and analysis of results. Oscar Núñez-Mata and Guillermo Jiménez-Estévez developed the practical considerations. Patricio Mendoza-Araya made a complete review and editing of the paper before it was submitted.

Conflicts of Interest: The authors declare no conflict of interest. 


\section{Appendix}

Table A1. Line data of the distribution grid of the ESUSCON microgrid.

\begin{tabular}{cccc}
\hline Line No. & $\mathbf{R}[\mathbf{\Omega} / \mathbf{k m}]$ & $\mathbf{X}[\mathbf{\Omega} / \mathbf{k m}]$ & Length $[\mathbf{k m}]$ \\
\hline L1-2 & 0.372 & 0.0890 & 0.0910 \\
L2-3 & 0.744 & 0.0930 & 0.0680 \\
L3-4 & 1.010 & 0.0965 & 0.178 \\
L3-5 & 0.744 & 0.0930 & 0.0250 \\
L5-6 & 1.010 & 0.0965 & 0.0440 \\
L5-7 & 0.744 & 0.0930 & 0.229 \\
L5-9 & 1.010 & 0.0965 & 0.0280 \\
L2-8 & 0.744 & 0.0930 & 0.0840 \\
L8-9 & 1.010 & 0.0965 & 0.148 \\
L8-11 & 1.010 & 0.0965 & 0.0370 \\
L9-10 & 1.010 & 0.0965 & 0.0890 \\
\hline
\end{tabular}

\section{References}

1. Oureilidis, K.; Demoulias, C. A fault clearing method in converter-dominated microgrids with conventional protection means. IEEE Trans. Power Electron. 2016, 31, 4628-4640. [CrossRef]

2. Lasseter, R. MicroGrids. In Proceedings of the 2002 IEEE Power Engineering Society Winter Meeting, New York, NY, USA, 7-31 January 2002; Volume 1, pp. 305-308.

3. Zeineldin, H.; Kanan, N.; Casagrande, E.; Woon, W. Data mining approach to fault detection for isolated inverter-based microgrids. IET Gener. Transm. Distrib. 2013, 7, 745-754.

4. Tumilty, R.; Patrick, R.; Fardo, W. Approaches to network protection for inverter dominated wlectrical distribution systems. IET Int. Conf. Power Electron. Mach. Drives 2006, 622-626. [CrossRef]

5. Kar, S.; Samantaray, S.; Zadeh, D. Data-Mining model based intelligent differential microgrid protection scheme. IEEE Syst. J. 2015, 11, 1161-1169. [CrossRef]

6. Bui, D.; Lien, K.; Chen, S.; Lu, Y.; Chan, C.; Chang, Y. Investigate dynamic and transient characteristics of microgrid operation and develop a fast-scalable-adaptable algorithm for fault protection system. Electr. Power Syst. Res. 2015, 120, 214-233. [CrossRef]

7. Brearley, B.; Prabu, R. A review on issues and approaches for microgrid protection. Renew. Sustain. Energy Rev. 2017, 67, 988-997. [CrossRef]

8. Urdaneta, A.; Nadira, R.; Jimenez, L. Optimal coordination of directional overcurrent relays in interconnected power systems. IEEE Trans. Power Deliv. 1988, 3, 903-911. [CrossRef]

9. Craparo, E.; Karatas, M.; Singham, D. A robust optimization approach to hybrid microgrid operation using ensemble weather forecasts. Appl. Energy 2017, 201, 135-147. [CrossRef]

10. Albasri, F.; Alroomi, A.; Talaq, J. Optimal coordination of directional overcurrent relays using biogeography-based optimization algorithms. IEEE Trans. Power Deliv. 2015, 30, 1810-1820. [CrossRef]

11. Bertsimas, D.; Litvinov, E.; Sun, X.; Zhao, J.; Zheng, T. Adaptive robust optimization for the security constrained unit commitment problem. IEEE Trans. Power Syst. 2013, 28, 52-63. [CrossRef]

12. Zamani, M.; Sidhu, T. A protection strategy and microprocessor-based relay for low-voltage microgrids. IEEE Trans. Power Deliv. 2011, 26, 1873-1883. [CrossRef]

13. Zarei, S.; Parniani, M. A comprehensive digital protection scheme for low voltage microgrids with inverter-based and conventional distributed generations. IEEE Trans. Power Deliv. 2017, 32, 441-452. [CrossRef]

14. Sharaf, H.; Zeineldin, H.; El-Saadany, E. Protection coordination for microgrids with grid-connected and islanded capabilities using communication assisted dual setting directional overcurrent relays. IEEE Trans. Smart Grid 2018, 9, 143-151. [CrossRef]

15. Ezzeddine, M.; Kaczmarek, R. A novel method for optimal coordination of directional overcurrent relays considering their available discrete settings and several operation characteristics. Electr. Power Syst. Res. 2011, 81, 1475-1481. [CrossRef] 
16. Jimenez, L.; Urdaneta, A. Optimal coordination of directional overcurrent relays considering definite backup relaying. IEEE Trans. Power Deliv. 1999, 14, 1276-1284.

17. Saleh, K.; Zeineldin, H.; El-saadany, E. Optimal coordination of directional overcurrent relays using a new time-current-voltage characteristic. IEEE Trans. Power Deliv. 2015, 30, 537-544. [CrossRef]

18. Saleh, K.; Zeineldin, H.; El-saadany, E. Optimal protection coordination for microgrids considering N-1 contingency. IEEE Trans. Ind. Inform. 2017, 13, 2270-2278. [CrossRef]

19. Sutherland, P.E. Protective device coordination in an industrial power system with multiple sources. IEEE Trans. Ind. Appl. 1997, 33, 1096-1103. [CrossRef]

20. Braga, A.; Saraiva, J. Coordination of overcurrent directional relays in meshed networks using the Simplex method. In Proceedings of the 8th Mediterranean Electrotechnical Conference on Industrial Applications in Power Systems, Computer Science and Telecommunications (MELECON 96), Bari, Italy, 16 May 1996; pp. 1535-1538.

21. Boyd, S.; Vandenberghe, L. Convex Optimization; Cambridge University Press: Cambridge, UK, 2004.

22. Nuñez, O.; Palma, R.; Valencia, F.; Mendoza, P.; Cotos, J. Integrated protection and monitoring system for safe operation of photovoltaic-based isolated microgrids. In Proceedings of the IEEE PES General Meeting, Chicago, IL, USA, 16-20 July 2017; pp. 1-5.

23. Palma-Behnke, R.; Benavides, C.; Lanas, F.; Severino, B.; Reyes, L.; Llanos, J.; Sáez, D. A microgrid energy management system based on the rolling horizon strategy. IEEE Trans. Smart Grid 2012, 4, 996-1006. [CrossRef]

24. Olivares, D.; Cañizares, C.; Kazerani, M. A centralized energy management system for isolated microgrids. IEEE Trans. Smart Grid 2014, 5, 1864-1875. [CrossRef]

25. Boutsika, T.; Papathanassiou, S. Short-circuit calculations in networks with distributed generation. Electr. Power Syst. Res. 2008, 78, 1181-1191. [CrossRef]

26. Nouri, H.; Terzija, V.V.; Rade, C. Improved fault analysis method based on a new arc resistance formula. IEEE Trans. Power Deliv. 2011, 26, 120-126.

27. IEEE PES. Distribution Test Feeders. 37-Bus Feeder. 2000. Available online: http://ewh.ieee.org/soc/pes / dsacom/testfeeders/index.html (accessed on 23 August 2017).

28. Alvial, C.; Garrido, N.; Jiménez, G.; Reyes, L.; Palma, R. A methodology for community engagement in the introduction of renewable based smart microgrid. Energy Sustain. Dev. 2011, 15, 314-323. [CrossRef]

29. Núñez, O.; Valencia, F.; Palma, R.; Jiménez, G.; Cotos, J. Microgrids Protection Schemes (esquemas de protección para micro-redes). In Proceedings of the 2015 CHILEAN Conference on Electrical, Electronics Engineering, Information and Communication Technologies (CHILECON), Santiago, Chile, 28-30 October 2015; pp. 1-6. 